\title{
Intergenerational waste
}

Energy Res. Social Sci. 50, 7-17 (2019)

Nuclear waste can have significant longterm impacts and intergenerational costs that are hard to estimate because of uncertainty about final disposal methods. Consequently, integrated assessment studies of energy systems often do not take into account these intergenerational costs. Robert Barron and Mary Hill at the University of Kansas now incorporate these long-term safe waste disposal costs into future scenarios and find that inclusion of them significantly reduces the economic competitiveness of nuclear energy.

The researchers use a waste management cost model that includes all expenses from initial cooling-pool storage to permanent disposal in a geological repository and follows the current US policy and practice. They explore six different scenarios with different levels of socioeconomic development and greenhouse gas emissions while considering three different cost scenarios for nuclear waste disposal. The new cost of nuclear is incorporated into the scenario results by assuming that if the cost including waste disposal is high, nuclear will not be a viable option and will not affect carbon abatement costs. The researchers find that over many cost and development scenarios, more realistic waste disposal costs render nuclear a less competitive option. They conclude that integrated assessments must take into account the long-term safe waste disposal costs of nuclear waste in order to not paint a potentially rosier than possible picture of abatement costs under high nuclear penetration.

Fouad Khan

Published online: 13 June 2019

https://doi.org/10.1038/s41560-019-0419-x 